\title{
RANCANG BANGUN SISTEM KETERSEDIAAN TEMPAT PARKIR MOBIL MENGGUNAKAN SENSOR INFRARED BERBASIS ARDUINO
}

\author{
Meidi Wani Lestari ${ }^{1 *}$, Novita Delima Siahaan ${ }^{2}$, Reynaldi Sianipar ${ }^{3}$. \\ 1,2,3 Politeknik Negeri Medan, Medan, Sumatera Utara, 20155, Indonesia \\ e-mail: meidilestari@polmed.ac.id, siahaannovitadelima@gmail.com, reynaldisianipar@gmail.com
}

\begin{tabular}{ccc}
\hline Diterima & Direvisi & Disetujui \\
$30-09-2021$ & $07-10-2021$ & $19-10-2021$ \\
\hline
\end{tabular}

\begin{abstract}
One of the difficulties of entering a skyscraper is parking. There is no information about the availability of parking slots in the building making it difficult to find a parking location. Therefore, an information system is needed to determine the availability of parking slots in a skyscraper. The common parking system just give information about the number of vehicles that enter the skyscraper without slot parking information. The objective of this study is to display the availability of parking slots using LDR sensors as parking slot monitoring and infrared sensors to count the number of vehicles. The results of this study are the parking slot system has succeeded in displaying parking conditions by displaying the availability of parking slots in a building and the number of cars parked in the building.
\end{abstract}

Keywords: Parking System; Infrared Sensors; LDR Sensor; Skyscraper

\begin{abstract}
Abstrak: Salah satu kesulitan memasuki gedung bertingkat adalah parkir. Tidak adanya informasi tentang ketersediaan slot parkir pada bangunan menyebabkan kesulitan untuk menemukan lokasi parkir. Oleh karena itu dibutuhkan sebuah sistem informasi untuk mengetahui ketersediaan slot parkir pada sebuah gedung bertingkat. Sistem parkir yang umumnya hanya mengetahui jumlah kendaraan yang masuk kedalam gedung bertingkat namun belum memiliki informasi tentang ketersediaan slot parkir. Tujuan penelitian ini adalah menampilkan ketersediaan slot parkir menggunakan sensor LDR sebagai monitoring tempat parkir dan sensor infra red untuk jumlah mobil yang mauk ke dalam mobil. Hasil dari penelitian ini adalah sistem slot parkir telah berhasil menampilkan kondisi parkir dengan menampilkan ketersediaan slot parkir pada sebuah gedung dan jumlah mobil yang parkir pada gedung tersebut.
\end{abstract}

Kata kunci: Sistem Parkir; Sensor infrared; Sensor LDR; gedung bertingkat

\section{PENDAHULUAN}

Kebutuhan akan informasi tentang ketersediaan slot parkir pada sebuah gedung bertingkat sangat diperlukan. Hal ini sangat dibutuhkan untuk efisiensi waktu dan kemudahan bagi pengendara yang berkegiatan pada gedung bertingkat. Pada kota besar kegiatan banyak sekali dilakukan pada gedung bertingkat seperti perkantoran, Rumah Sakit, Apartemen dan tempat perbelanjaan sangat membutuhkan sebuah sistem yang dapat memberikan kemudahan dan kenyamanan bagi pengendara untuk mengetahui ketersediaan slot parkir. Penelitian tentang sistem parkir menggunakan optocoupler sensor dan mikrokontroler WiDo telah berhasil memberikan informasi tentang ketersediaan lokasi parkir dan jumlah kendaraan (Yulianto, 2016). Penggunaan DT-Sense IR Proximity Detector sebagai sistem ketersediaan parkir otomatis telah dilakukan dengan menampilkan LED berwarna merah dan buzzer jika area parkir telah penuh terisi (Sunandar,2017). Pada penelitian tentang ketersediaan slot parkir menggunakan sensor ultrasonik berbasis arduino untuk pada sebuah gedung (Putra, 2020). Penggunaan sistem parkir melalui website dan sensor 
ultrasonik telah dilakukan untuk memudahkan pengguna mengetahui ketersediaan slot parkir pada gedung (Izzatuffikri,2019). Sistem parkir otomatis berbasis Internet of Things dengan menggunakan sensor ultrasonik juga telah dilakukan untuk memudahkan pengguna yang akan memasuki gedung bertingkat (Indah, 2018).

Tujuan Penelitian ini adalah rancang bangun sistem ketersediaan slot parkir pada gedung bertingkat menggunakan sensor infra-red berbasis arduino. Penggunaan sensor infra-red digunakan pada sistem parkir pada pesantren Nurul jadid untuk menggantikan peran manusia dalam monitoring area parkir. Jika masih tersedia area parkir, maka sensor infra-red akan memberikan sinyal pada motor servo untuk membuka palang pintu sehingga kendaraan dapat memasuki area pesantren (Rahman,2019). Penggunaan sensor infra red selain digunakan untuk membuka palang pintu parkir otomatis juga digunakan untuk membuka dan menutup kran air otomatis untuk penggunaan wudhu (Faisal, 2020). Penggunaan sensot infrared berbasis Raspberry Pi dengan tampilan LED juga telah berhasil dilakukan untuk mengetahui ketersediaan parkir pada sebuah gedung dan ditambahkan kamera untuk keamanan (Nataliana, 2014). Penggunaan sensor infrared dan penambahan kartu RFID juga dilakukan untuk sistem parkir otomatis. Kartu RFID berfungsi untuk mengenali dan membatasi orang yang dapat masuk ke area parkir sebuah gedung (Arifin,2019). Penerapan metode fuzzy dilakukan untuk mengetahui ketersediaan parkir dimana fuzzy diperuntukkan membaca kondisi input yang dikirimkan oleh sensor infrared dan photodioda (Fawwaz,2019).

\section{METODE PENELITIAN}

Tahapan penelitian rancang bangun sistem ketersediaan parkir dapat dilihat pada gambar 1. Rancang bangun dari sistem ini terdiri beberapa blok yaitu adaptor, penurun tegangan, sensor infrared, sensor LDR, Wi-Fi, NodeMCU, Arduino Atmega2560, Firebase, Website, Monitor Laptop, Motor Servo, LCD, LED.

Gambar 1 terdiri dari beberapa blok yang memiliki tugas masing-masing. Adaptor merupakan alat yang berfungsi untuk mengubah arus AC menjadi DC dengan besaran tegangan tertentu yang sesuai dengan kebutuhan beban. Adaptor juga berfungsi sebagai alat untuk menyambungkan sumber tegangan DC atau juga menjadi alternatif pengganti tegangan DC seperti baterai atau Aki. Penggunaan penurun tegangan LM2596 adalah untuk menurunkan tegangan dari 9VDC menjadi 5 VDC untuk menyuplai tegangan ke Arduino Mega.

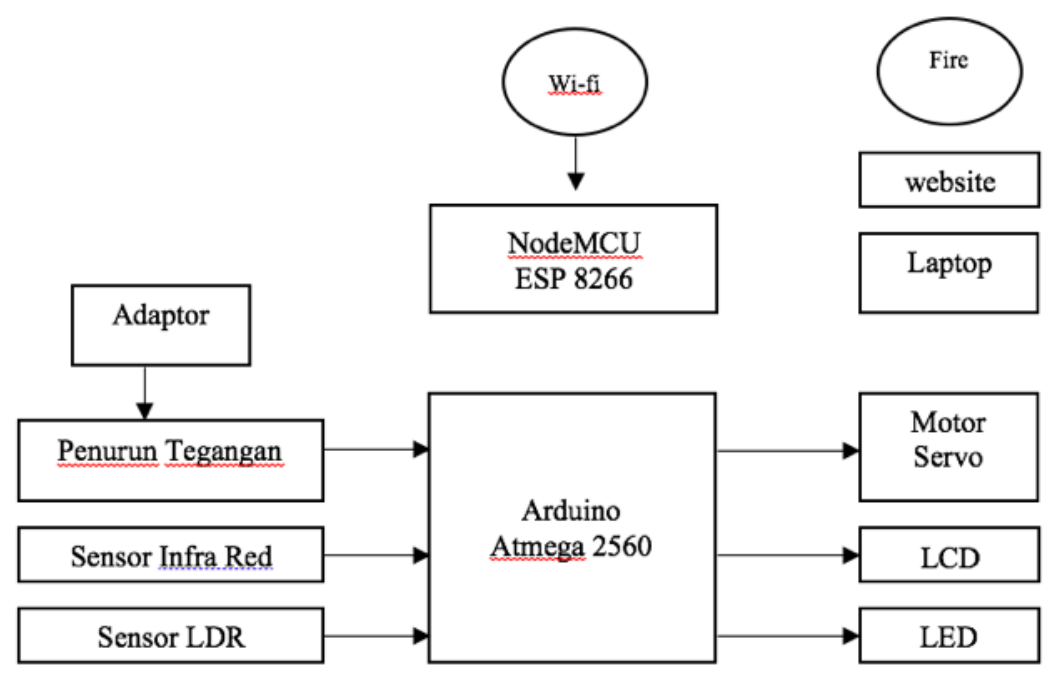

Gambar 1. Diagram blok rangkaian 
Sensor Infrared adalah sensor yang bekerja untuk mendeteksi ada tidaknya mobil yang ingin masuk atau keluar area parkir sedangkan sensor LDR adalah sensor yang berfungsi untuk mendeteksi adatidaknya mobil yang mengisi slot parkir. Wi-fi digunakan untuk menghubungkan dan mengirimkan data dari arduino mega ke firebase. Pada penelitian ini arduino mega 2560 merupakan mikrokontroller pada sistem yang merupakan pusat kontrol dari semua proses kerja sistem berlangsung. Fire base sebagai tempat menyimpan dan menerima data yan dikirim oleh NdoeMCU ESP8266 dan mengirimnya ke website. Website berfungsi untuk menampilkan/memonitoring secara real time keadaan tempat parkir, sehingga petugas dapat mengetahui dimana saja slot parkir yang masih kosong atau sudah terisi. Motor servo berfungsi untuk membuka dan menutup gerbang parkir. Sedangkan LCD berfungsi untuk informasi ketersediaa slot parkir kepada pengemudi. LED merupakan indikator yang berfungsi untuk memberitahu kepada pengemudi slot area yang telah terisi.

Tegangan 220V mengalir ke Adaptor 12V/1 A. Kemudian tegangan dariAdaptor 12V/1 A akan diturunkan oleh penurun tegangan LM2596 menjadi 5 V. Kemudian power ini akan dialirkan ke Arduino Mega 2560 danNodeMCU ESP8266 agar aktif. Ketika sensor Infrared menerima sinyal atau mendeteksi sebuah objek/mobildan akan langsung dikirim ke Arduino Mega 2560 maka motor servo akan aktif. Ketika sensor LDR menerima sinyal atau mendeteksi sebuah objek/mobil maka LED akan mati. Data LDR akan langsung dikirim ke Arduino Mega 2560 dan akan diteruskan ke NodeMCU ESP8266 maka NodeMCU ESP8266 akan mengirimkan data ke firebase, dan firebase akan mengirimkan data ke Website.

Rangkaian skematik dari rancang bangun sistem ketersediaan slot parkir pada penelitian ini dapat dilihat pada gambar 2. Dari gambar 2 dapat dilihat bahwa 5 buah sensor LDR dan 5 buah LED sebagai indikator.LDR mempunyai 2 kaki, yang mana kaki LDR terhubung ke $\mathrm{V}_{\mathrm{CC}}$ pada Arduino Mega dan kaki kanannya terhubung ke pin Analog pada Arduino Mega. LED mempunyai 2 kaki yaitu Anoda (+) dan Katoda (-), yang mana kaki Anoda terhubung ke kaki kanan LDR dan kaki kkirinya terhubung kePin Arduino Mega.

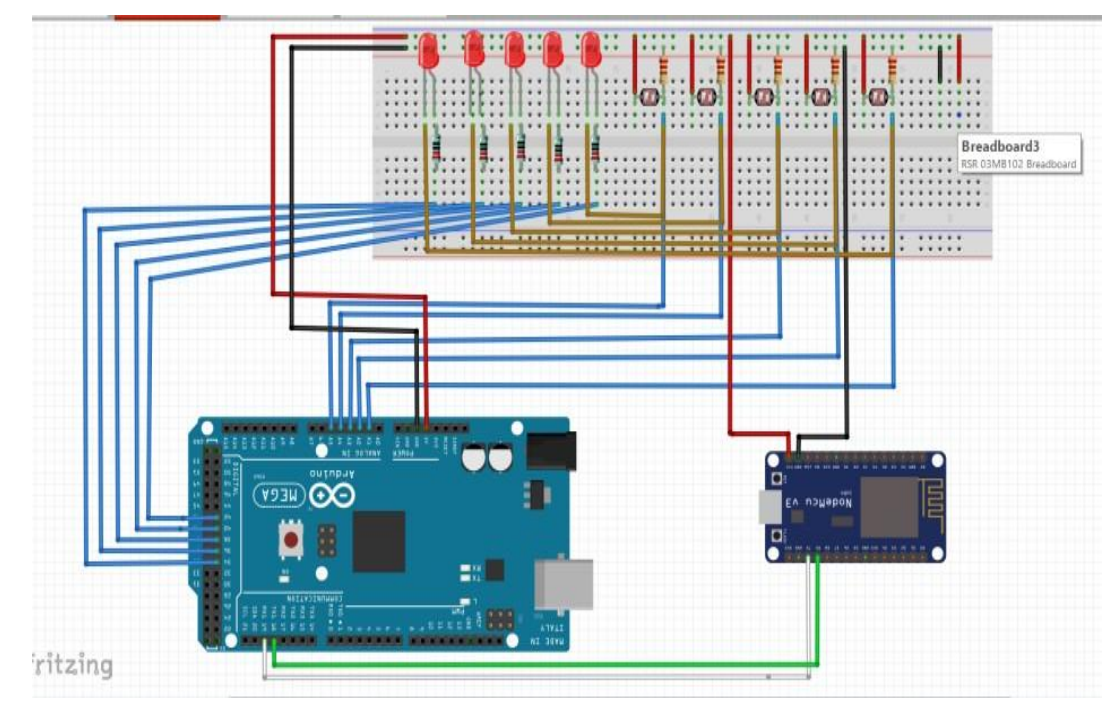

Gambar 2. Rangkaian Skematik Sistem Ketersediaan Slot Parkir 


\section{HASIL}

Dalam pengujian keseluruhan alat semua sensor dan komponen lainnyasudah digabung menjadi satu. Dalam hal ini akan menampilkan slot parkir yang kosong, slot parkir terisi satu persatu sampai slot parkir terisi penuh semua. LCD dan Website akan menampilkan keadaan tempat parkir sehingga pengemudi mobil dan petugas dapat mengetahui keadaan tempat parkir. Alat ini menggunakan tegangan sebesar 5 VDC, dalam percobaan ini digunakan sumber tegangan dari Adaptor 12V yang diturunkan oleh penurun tegangan LM2596 menjadi 5 VDC. Saat sistem sudah dalam kondisi aktif maka LCD akan menampilkan jumlah ketersediaan tempat parkir dan Website juga akan menampilkan keadaan tempat parkir.

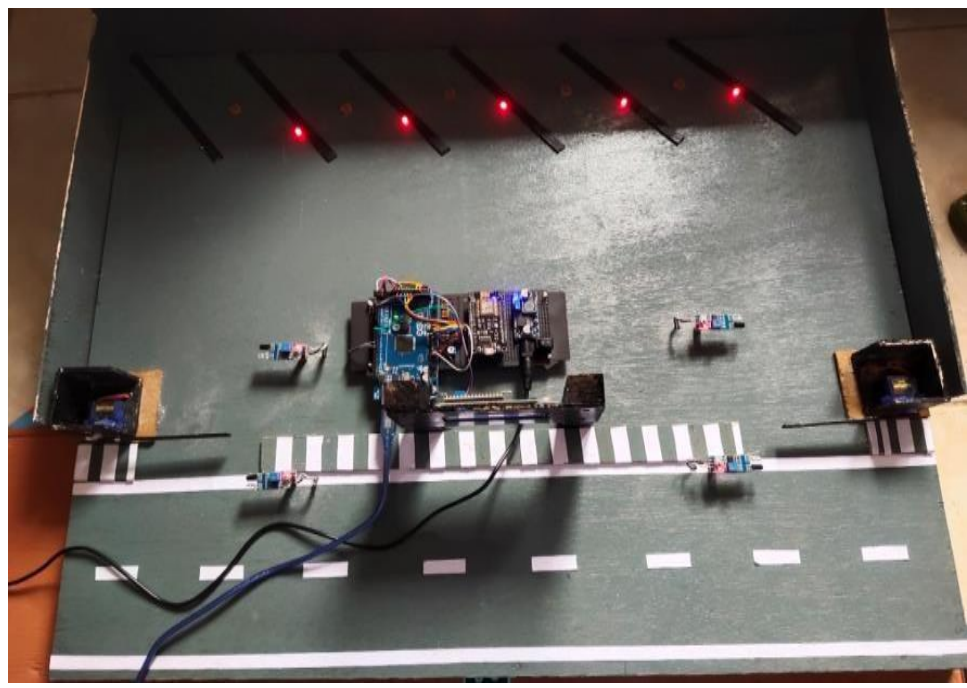

Gambar 3. Kondisi awal pengujian data

Gambar 3 menunjukkan kondisi saat awal pengujian data. Dapat dilihat pada slot parkir yang kosong maka LED akan meyala untuk mempermudah pengemudi menemukan area parkir yang masih tersedia. Informasi ini akan ditampilkan pada layar monitor yang dikirimkan oleh NodeMCU pada website sehingga pengemudi yang akan memasuki gedung dapat melihat informasi ketersediaan tersebut pada website. Gambar 4 merupakan tampilan sistem informasi pada website. Pada penelitian ini digunakan lima buah slot area parkir yang akan dimonitor ketersediaan slot parkir. Jika LED menyala seperti yang ditunjukkan oleh Gambar 3 maka tampilan pada website akan dapat dilihat pada Gambar 4. Gambar 4 menunjukkan monitoring web slot parkir dimana kondisi kelima slot tersebut dalam keadaan kosong.

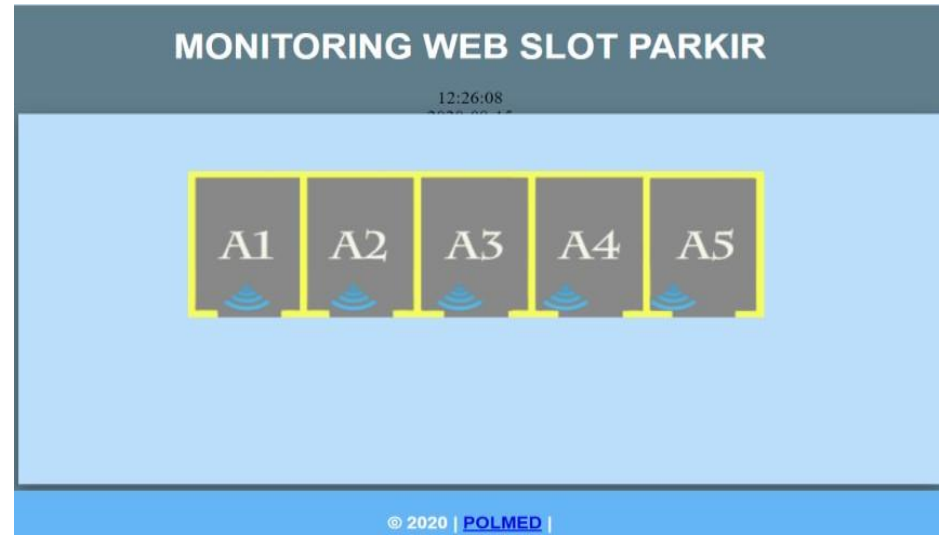

Gambar 4. Monitoring web slot parkir 


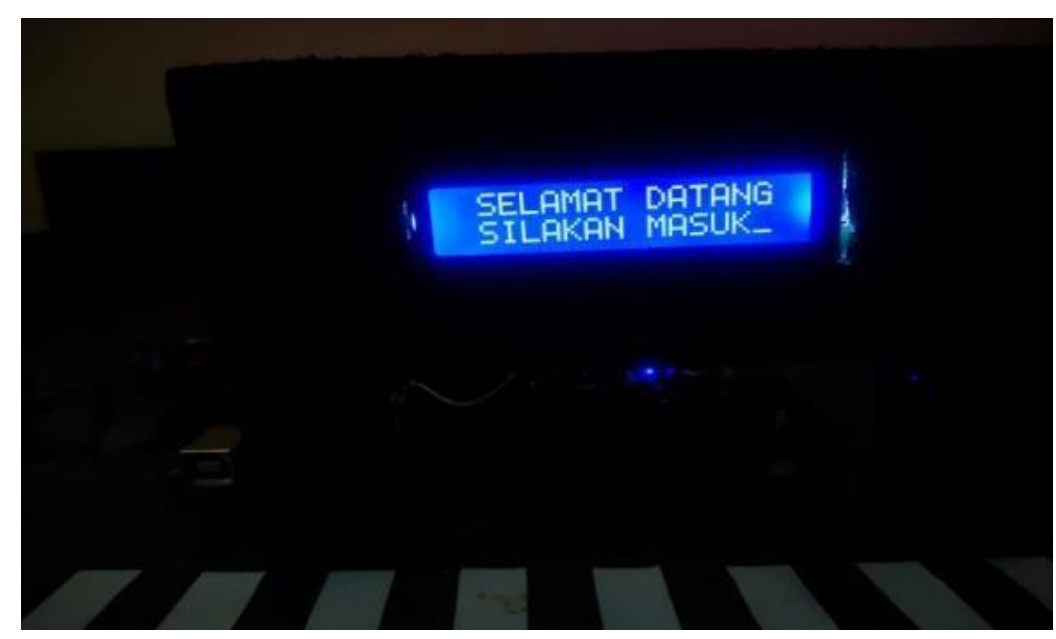

Gambar 5. Tampilan LED pada gerbang gedung

Gambar 5 menunjukkan tampilan LED ketika kendaraan masuk ke gedung bertingkat dimana tersedianya slot parkir. Sensor infrared berfungsi untuk mendeteksi kedatangan kendaraan yang akan masuk kedalam gedung. Ketika sensor mendeteksi adanya objek yang datang maka sensor akan mengirimkan sinyal pada Arduino untuk menggerakkan motor servo. Motor servo akan bekerja $150^{\circ}$ untuk membuka portal dan ketika kendaraan telah melewati portal akan menutup kembali $45^{\circ}$. Dan tampilan pada LCD adalah "Selamat Datang Silahkan Masuk" seperti yang ditunjukkan pada gambar 5. Ketika kendaraan telah berhenti pada slot parkir maka LED akan mati dan informasi ini akan ditampilkan pada LCD tentang jumlah slot parkir yang masih tersedia. Pada kondisi ini website akan menampilkan keadaan slot parkir yang telah terisi dan yang masih tersedia.

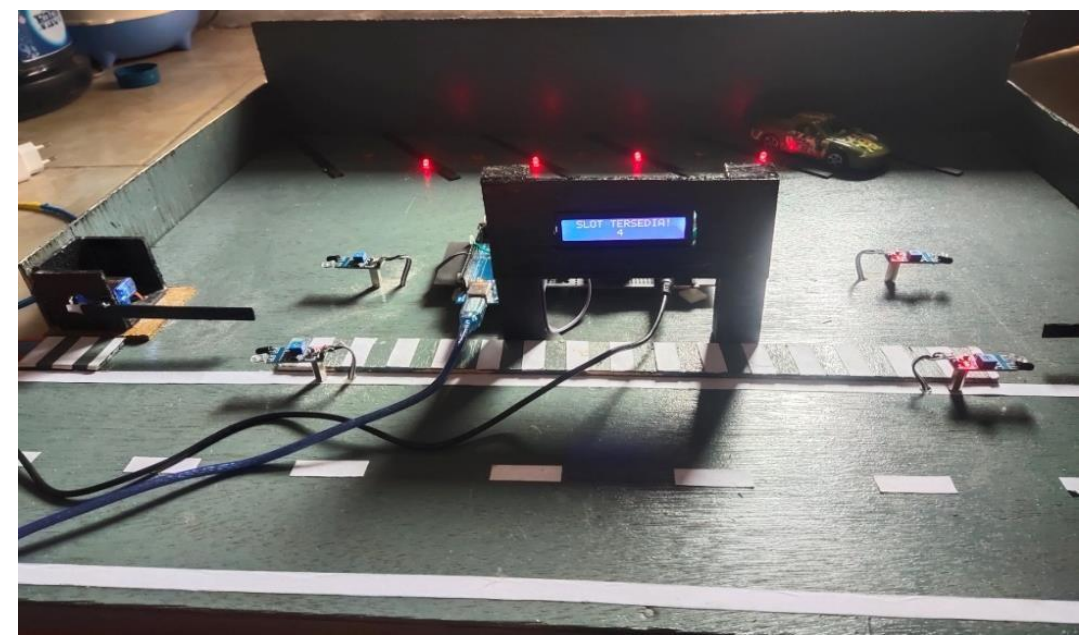

Gambar 6. Kondisi LED ketika ada mobil parkir

Gambar 6 menunjukkan kondisi dimana dari lima slot parkir yang tersedia telah terisi satu slot parkir. Pada slot parkir yang telah terisi menunjukkan bahwa LED telah padam sedangkan pada area yang masih kosong kondisi LED terlihat menyala. Ini menunjukkan bahwa LED telah bekerja dengan baik. Indikator LED ini sangat berperan bagi pengemudi yang telah memasuki gedung parkir yang pada umumnya gelap. Sehingga dengan bantuan LED akan dengan mudah memberikan informasi tentang lokasi slot area parkir gedung bertingkat. Ketersediaan slot parkir ini juga dapat 
diketahui di portal utama gedung melalui website. Dengan satu slot area parkir yang telah terisi dan yang masih kosong. Tampilan Pada website dapat dilihat pada Gambar 7.

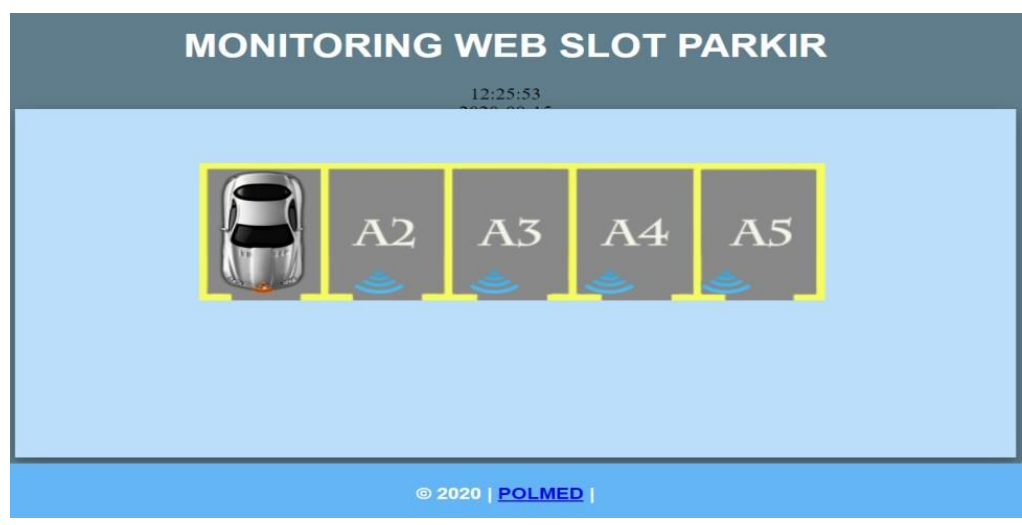

Gambar 7. Tampilan website ketersediaan slot parkir

Gambar 7 merupakan tampilan website ketika satu slot parkir terisi dan masih tersedia 4 slot parkir lagi. Sehingga dengan tampilan ini pengemudi dapat dengan mudah mengetahui tentang informasi keberadaan ketersediaan parkir.

\section{PEMBAHASAN}

Berdasarkan analisa kubutuhan sensor modul infrared digunakan sebagai pendeteksi mobil yang ingin masuk dan keluar dari lahan parkir, sensor ini bekerja dengan mengirimkan data digital ke Arduino Mega agar Arduino Mega memerintakan motor servo bekerja sesuai dengan perintah. Pada bagian sensor modul infrared terdapat trimpot yang berfungsi sebagai pengatur jarak untuk mendeteksi objek. Agar sensor modul infared dapat mendeteksi mobil dengan baik atau sesuai jarak yang di inginkan maka trimpot harus diputar.

Dan berdasarkan analisa kebutuhan sensor LDR digunakan sebagai pendeteksi ada tidaknya mobil di slot parkir, sensor ini bekerja dengan mengirim data analog ke Arduino Mega dan akan ditampilkan di LCD. Datajuga akan diteruskan ke NodeMCU ESP8266 untuk dilanjutkan ke firebase kemudian akan ditampilkan ke website. Sensor LDR sangat sensitif terhadap cahaya ketika sensor LDR berada di tempat yang terang maka resistansi akan berkurang dan ketika sensor LDR berada ditempat yang gelap maka resistansi akan bertambah.

Hasil data dari Arduino Mega yang sudah diteruskan ke NodeMCU ESP8266 akan dikirim ke firebase dan ditampilkan di Website. Tampilan yang dapat dilihat di website ada ketika slot parkir kosong, slot parkir mulai terisi dan slot parkir penuh. Tampilan pada website sangat bergantung pada koneksi internet, jika koneksi internet bagus maka website dapat menampilkan secara realtime namun website akan sering offline jika koneksi internet buruk atau kurang bagus

\section{KESIMPULAN}

Sensor infrared telah bekerja dengan baik untuk membaca data dan mengirimkan data ke mikrokontroler untuk menggerakkan motor servo. Untuk memperoleh pembacaan sensor yang baik dibutuhkan kalibrasi agar sesuai dengan lingkungan sekitar. Website juga telah berhasil memberikan informasi tentang ketersediaan slot parkir pada sebuah gedung. 


\section{REFERENSI}

Yulianto, N., \& Bacharuddin, F. (2016). Perancangan Sistem Informasi Parkir dengan WiFi Berbasis Arduino. Lontar Komput. J. Ilm. Teknol. Inf, 7(3, p).

Sunandar, E., Saefullah, A., \& Meka, Y. Q. (2017). Prototype Monitoring Area Parkir Mobil Berbasis Arduino Uno Untuk Mendeteksi Ketersediaan Slot Parkir Secara Otomatis. Creative Communication and Innovative Technology Journal, 10(1), 83-97.

Putra, R. A. A., \& Nurgiyatna, S. T. (2017). Sistem Informasi Ketersediaan Slot Parkir Menggunakan Arduino Uno (Doctoral dissertation, Universitas Muhammadiyah Surakarta).

Izzatuffikri, E. (2019). PROTOTYPESISTEM DETEKSI KETERSEDIAAN SLOT PARKIR MOBIL BERBASIS MIKROKONTROLLER (Doctoral dissertation, Universitas Pasundan).

Indah, P. F. (2018). SISTEM MONITORING KETERSEDIAAN TEMPAT PARKIR DAN PEMANDU LOKASI PARKIR MOBIL BERBASIS TEKNOLOGI INTERNET OF THINGS (Doctoral dissertation, Universitas Andalas).

Rahman, F., \& Sulistiyanto, S. (2019). Prototipe Palang Pintu Parkir Otomatis dan Informasi Parkir Kendaraan Roda Empat di Pondok Pesantren Nurul Jadid dengan Sensor Infra Red Berbasis Mikrokontroller. JEECOM: Journal of Electrical Engineering and Computer, 1(1).

Faisal, M., \& Arsianti, R. W. (2020). Sistem Kran Air Otomatis Menggunakan Sensor Infrared Ajdustable. Elektrika Borneo, 6(1), 20-24.

Nataliana, D., Syamsu, I., \& Giantara, G. (2014). Sistem Monitoring Parkir Mobil menggunakan Sensor Infrared berbasis RASPBERRY PI. ELKOMIKA: Jurnal Teknik Energi Elektrik, Teknik Telekomunikasi, \& Teknik Elektronika, 2(1), 68.

Arifin, M., \& Hartayu, R. (2019). Sistem Parkir Menggunakan Kartu RFID. Jurnal ELSAINS PISSN, 2527, 6336.

Fawwaz, I., Azmi, F., Muhathir, M., \& Dharshinni, N. P. (2019). Design of Parking Control Using Ultrasonic Sensor Based On Fuzzy Logic. JOURNAL OF INFORMATICS AND TELECOMMUNICATION ENGINEERING, 3(1), 155-162. 